\title{
Why internationally adopted children should be screened for tuberculosis
}

\section{Richard Long MD, Jody Boffa MIH}

$\mathrm{P}$ ediatric tuberculosis is important medically and indicative of a public health problem. Once infected with $M y$ cobacterium tuberculosis, children are at increased risk of tuberculosis disease, including severe forms such as central nervous system and disseminated tuberculosis. ${ }^{1,2}$ The risk is highest among children less than 5 years of age and is especially high among infants. ${ }^{1,2}$ Tuberculosis in children usually reflects recent transmission from an infectious adolescent or adult. ${ }^{1,2}$ In Canada, pediatric tuberculosis largely affects 2 groups: Canadian-born children of Aboriginal ancestry, and foreign-born children or Canadian-born children of foreignborn parents. ${ }^{3,4}$ For the foreseeable future, any decline in the incidence of pediatric tuberculosis in Canada is expected to be modest, whereas the proportion of cases related to immigration is expected to increase (Table $\mathrm{I})^{2-5}$

In Canada the immigration medical examination has limited application to children: all immigrant applicants, refugees and certain visitors are required to undergo an immigration medical examination to identify those who may pose a risk to public health or to public safety or those who may place excessive demands on Canadian health and social services. ${ }^{2}$ Immigration medical examinations are required for 2 types of visitors, of which only the first is applicable to children: visitors who have lived in a designated country for 6 or more consecutive months in the year preceding the date of seeking entry to Canada and who are intending to stay in Canada for at least 6 months; and visitors intending to work in an occupation where protection of public health is essential (e.g., teachers and physicians), regardless of their country of origin or anticipated length of stay in Canada. The Public Health Agency of Canada uses the World Health Organization's estimated incidence rates of tuberculosis (www.phac-aspc.gc.ca/tbpc-latb/itir_e.html) to determine

Table 1: Pediatric tuberculosis in Canada, 1970-2005, by ethnic group

No. (\%) of cases

of pediatric tuberculosis

\begin{tabular}{lrrrr}
\cline { 2 - 5 } Ethnic group & $1970-1995$ & \multicolumn{2}{c}{$1996-2005$} \\
\hline Canadian-born Aboriginal & 3140 & $(53.1)$ & 651 & $(56.5)$ \\
Canadian-born non-Aboriginal & 2240 & $(37.9)$ & 266 & $(23.1)$ \\
\hline Foreign born & 530 & $(9.0)$ & 226 & $(19.6)$ \\
\hline Unknown & 0 & 10 & $(0.9)$ \\
\hline All & 5910 & $(100.0)$ & $1153(100.0)$ \\
\hline
\end{tabular}

Sources: Phypers ${ }^{3}$ and the Public Health Agency of Canada. ${ }^{5}$ which countries are designated for the purpose of visitor medical examinations.

The immigration medical examination consists of a medical history, physical examination and 4 age-related routine tests: urinalysis (for applicants 5 years or older), chest radiograph (for applicants in years or older), syphilis serology (for applicants I5 years or older) and HIV serology (for applicants I5 years or older). The immigration medical examination is not aimed at detecting latent tuberculosis infection (an asymptomatic condition of infection without disease) or tuberculosis disease in children under II years of age (an asymptomatic or symptomatic condition of disease usually associated with an abnormal chest radiograph), in large part because these conditions, although of importance to the individual, are not of immediate importance to public health. Primary pulmonary tuberculosis in a child under the age of ro or II years is usually paucibacillary and rarely infectious. ${ }^{2}$

Foreign-born children with tuberculosis usually belong to one or other class applying for permanent residence (economic, family, protected persons [refugees] or other), although they may also be visitors. Within this classification system, international adoptees constitute a unique subgroup of family class applicants. ${ }^{6}$ Most are less than 5 years of age. They frequently come from resource-poor countries where infectious diseases such as tuberculosis and intestinal parasites are common and prenatal screening for infectious diseases such as syphilis, hepatitis B and HIV infection may be uncommon. Many have suffered prolonged periods of abandonment or deprivation for which no medical history can be obtained. National ${ }^{7}$ and international publications ${ }^{8-11}$ emphasize the need for thorough screening upon arrival and the importance of screening tests in addition to the medical history and physical examination.

Although required of all immigrants, ${ }^{6}$ the immigration medical examination as summarized earlier is not designed to meet the specific medical screening needs of international adoptees. Overseas testing, if performed, may be unreliable or outdated the immigration medical examination can precede the child's arrival in Canada by up to I2 months., ${ }^{2,710}$ The screening needs of international adoptees should be met by the province or territory and family into whose care the child has been placed. Ideally, all international adoptees should undergo timely screening after arrival in Canada for a range of conditions endemic to their country of origin. ${ }^{2,10,11}$ Nominal notification of the province or territory of the child's arrival might prompt a letter reminding

Richard Long and Jody Boffa are with the Tuberculosis Program Evaluation and Research Unit, University of Alberta, and Alberta Health and Wellness, Edmonton, Alta. 
adoptive families of the need for this screening. Screening in Canada should be conducted by experienced physicians or specialty clinics familiar with country-specific disease patterns, and where laboratory testing may be undertaken in a consistent and standardized manner. Diagnoses of notifiable communicable diseases must be reported to provincial or territorial authorities. Provinces and territories should ensure that the costs of screening tests pose no obstacle to their performance.

In Alberta, from 2004 to $2006,40 \%$ (4/IO) of the foreign-born children aged less than 5 years who were found to have tuberculosis were international adoptees. This translates into a crude incidence rate of tuberculosis of about 4 per 23I international adoptees in this age group, or 1732 per 100 ooo adoptees (23I children aged less than 5 years were approved for adoption in Alberta from 2004 to 2006). ${ }^{12}$ This incidence rate is 200 times the estimated rate of tuberculosis among foreign-born children aged less than 5 years in Alberta from 1990 to 2004 (8.54 per I00 000 person-years). ${ }^{4}$ The 4 adoptee cases were independent of one another and presented within $36-138$ days after arrival in Canada. All had been living in orphanages in their country of origin. All had primary pulmonary tuberculosis; 3 had positive cultures. Their isolates of $M$. tuberculosis were susceptible to all first-line antituberculosis drugs and had unique genotypes when compared with historical isolates, which suggests an overseas origin. Three of the 4 adoptee cases had been referred to tuberculosis services because of a positive tuberculin skin test result.

As a high-risk population, all international adoptees should be screened upon arrival in Canada for latent tuberculosis infection with the use of the Mantoux tuberculin skin test. The result should be interpreted by a health care professional within $48-72$ hours after placement (Table 2). ${ }^{13}$ For children who initially have a reaction of less than $10 \mathrm{~mm}$ induration, a repeat tuberculin skin test 3-6 months after arrival should be considered because some children may have diminished reactivity related to malnu-

Table 2: Interpretation of tuberculin skin test reactions

\begin{tabular}{|c|c|}
\hline $\begin{array}{l}\text { Reaction size, } \\
\text { mm induration }\end{array}$ & $\begin{array}{l}\text { Situation in which reaction } \\
\text { is considered positive* }\end{array}$ \\
\hline$\leq 4$ & $\begin{array}{l}\text { HIV infection with immune suppression } \\
\text { and high expected likelihood of latent } \\
\text { tuberculosis infection (e.g., patient is } \\
\text { from a population with a high prevalence } \\
\text { of tuberculosis infection, is a close } \\
\text { contact of an active contagious case or } \\
\text { has an abnormal chest radiograph) }\end{array}$ \\
\hline $5-9$ & $\begin{array}{l}\text { - HIV infection } \\
\text { - Close contact of active contagious case } \\
\text { - Children suspected of having tuberculosis } \\
\text { disease } \\
\text { - Abnormal chest radiograph with } \\
\text { fibronodular changes } \\
\text { - Other severe immune suppression }\end{array}$ \\
\hline$\geq 10$ & - All others \\
\hline
\end{tabular}

*Positive reactions are reported as such regardless of the history of bacille Calmette-Guérin vaccination. ${ }^{13}$

Source: Canadian Tuberculosis Standards, 6th edition (draft), Public Health Agency of Canada, 2007. Reproduced and adapted with permission of the Minister of Public Works and Government Services Canada, 2007. trition or they may have been recently infected with insufficient time to mount an immune response. ${ }^{11}$ The benefits of repeat testing (diagnosis of latent tuberculosis infection and possibly active tuberculosis) may outweigh the risks (erroneous diagnosis of latent tuberculosis infection because of a false-positive skin test result). Children with a positive tuberculin skin test result or symptoms suggestive of tuberculosis should be examined for evidence of active disease and a chest radiograph performed. Children with latent tuberculosis infection or active tuberculosis disease should be treated in accordance with the Canadian Tuberculosis Standards. ${ }^{2}$ If the child was previously in an orphanage or children's home, the provincial or territorial tuberculosis program should, in consultation with the adoptive family, notify the orphanage or home as well as the adoption agency.

Because of numerous social and demographic circumstances, the availability of Canadian-born babies for adoption is limited, which increases the number of people seeking to adopt children from abroad. Systematic screening in Canada of these children is an imperative, both to the child and to the child's adoptive family and community.

This article has been peer reviewed.

Competing interests: None declared.

Contributors: Richard Long contributed to the conception, design and drafting of the article. Jody Boffa contributed to the acquisition of data and revised the article critically for important intellectual content. Both authors approved its final form.

Acknowledgements: We are very grateful to Edward Ellis MD, Public Health Agency of Canada, and Brian Gushulak MD, Migration Health Consultants Inc., Vienna, for their review of the manuscript, and to the staff of the Alberta TB Control Program (Alberta Health and Wellness, Calgary Region TB Clinic and Capital Region TB Clinic) for their verification of case data.

\section{REFERENCES}

I. Loeffler AM. Pediatric tuberculosis. Semin Respir Infect 2003;18:272-9I.

2. Canadian tuberculosis standards. 6th ed [draft]. Ottawa: Public Health Agency of Canada; 2007. Available: www.publichealth.gc.ca/tuberculosis.

3. Phypers M. Pediatric tuberculosis in Canada. Can Com Dis Rep 2003;20:I39-42.

4. Yip D, Bhargava D, Yao Y, et al. Pediatric tuberculosis in Alberta: epidemiology and case characteristics (1990-2004). Can J Public Health. In press.

5. Tuberculosis in Canada [annual]. Ottawa: Public Health Agency of Canada I996-2005 (pre-release data for 2004 and 2005). Available: www.phac-aspc.gc.ca /tbpc-latb/surv_e.html (accessed 2007 May 22).

6. International adoption and the immigration process. Ottawa: Citizenship and Immigration Canada; 2000. Cat no Ci63-I8/2000. Available: http://dsp-psd.pwgsc.gc ca/Collection/Ci63-18-2000E.pdf (accessed 2007 June 15).

7. Children and youth new to Canada: a health care guide. Ottawa: Canadian Paediatric Society; I 999.

8. Hostetter MK, Iverson S, Thomas W, et al. Medical evaluation of internationally adopted children. N Engl JMed I99I;325:479-85.

9. Saiman L, Aronson J, Zhou J, et al. Prevalence of infectious diseases among internationally adopted children. Pediatrics 2001;108:608-12.

Io. Staat MA. Infectious disease issues in internationally adopted children. Pediatr Infect Dis J 2002;21:257-8.

II. Barnett ED. Immunizations and infectious disease screening for internationally adopted children. Pediatr Clin North Am 2005;52:1287-309.

I2. Program Quality and Standards Division, Alberta Children's Services. International adoption: a guide for Alberta families. Edmonton: Alberta Children's Services; 2004. Available: www.child.gov.ab.ca/whatwedo/adoption/pdf/IntlGuideBook.pdf (accessed 2007 May 24).

I3. Farhat M, Greenaway C, Pai M, et al. False positive tuberculin skin tests: What is the absolute effect of BCG and non-tuberculous mycobacteria? Int J Tuberc Lung Dis 2006;10:1192-204.

Correspondence to: Dr. Richard Long, Rm. 8325, Aberhart

Hospital, II402 University Avenue, Edmonton AB T6G 2J3;

fax 780 407-I429; richard.long@ualberta.ca 